\title{
Article \\ Hydrogenation of Carboxyl Nitrile Butadiene Rubber Latex Using a Ruthenium-Based Catalyst
}

\author{
Xiaodong Liu ${ }^{1}$, Yunlei Fu ${ }^{1,2}$, Defang Zhou ${ }^{2}$, Hanchu Chen ${ }^{1}$, Yanyan $\mathrm{Li}^{1, *}$, Jianhui Song ${ }^{1, *} \mathbb{C}$, Shouyan Zhang ${ }^{3}$ \\ and Hui Wang $1,2, * \mathbb{D}$
}

check for

updates

Citation: Liu, X.; Fu, Y.; Zhou, D.; Chen, H.; Li, Y.; Song, J.; Zhang, S.; Wang, H. Hydrogenation of Carboxyl Nitrile Butadiene Rubber Latex Using a Ruthenium-Based Catalyst.

Catalysts 2022, 12, 97. https:// doi.org/10.3390/catal12010097

Academic Editor:

Miguel Martínez-Calvo

Received: 21 December 2021

Accepted: 11 January 2022

Published: 14 January 2022

Publisher's Note: MDPI stays neutral with regard to jurisdictional claims in published maps and institutional affiliations.

Copyright: (C) 2022 by the authors. Licensee MDPI, Basel, Switzerland. This article is an open access article distributed under the terms and conditions of the Creative Commons Attribution (CC BY) license (https:// creativecommons.org/licenses/by/ $4.0 /)$.
1 Shandong Provincial Key Laboratory of Olefin Catalysis and Polymerization, Key Laboratory of Rubber-Plastics of Ministry of Education, School of Polymer Science and Engineering, College of Chemistry and Molecular Engineering, Qingdao University of Science and Technology, Qingdao 266042, China; liuxiaodong122333@163.com (X.L.); fuyunlei@qust.edu.cn (Y.F.); cicy_0522@163.com (H.C.)

2 Shandong Provincial Key Laboratory of Olefin Catalysis and Polymerization, Yellow River Delta Jingbo Chemical Research Institute Co., Ltd., Binzhou 256500, China; zhoudefang66@163.com

3 Research and Development, Shangdong Dongdu Auto Parts Co., Ltd., Rizhao 276800, China; 15106332369@163.com

* Correspondence: liyanyan6771@163.com (Y.L.); jhsong@qust.edu.cn (J.S.); hwang@qust.edu.cn (H.W.)

\begin{abstract}
Hydrogenated carboxyl nitrile rubber (HXNBR) is endowed with superior mechanical performance and heat-oxygen aging resistance via emulsion hydrogenation of its precursor, i.e., carboxyl nitrile rubber (XNBR). Herein, a ruthenium-based catalyst was prepared to achieve the direct catalytic hydrogenation of XNBR latex. The effects of a series of hydrogenation conditions, such as catalyst dosage, solid content and reaction temperature, as well as the hydrogen pressure, on the hydrogenation reaction were investigated in detail. We found that the hydrogenation rate fell upon increasing the solid content of the XNBR latex, with an XNBR conversion rate of $95.01 \mathrm{~mol} \%$ in $7 \mathrm{~h}$ with $11.25 \mathrm{wt} \%$ solid content. As the reaction temperature was increased, the hydrogenation rate first increased and then decreased. The fastest reaction hydrogenation rate was reached at $140{ }^{\circ} \mathrm{C}$, with an XNBR conversion of $95.10 \mathrm{~mol} \%$ in $5 \mathrm{~h}$. The hydrogenation rate was positively related with the hydrogen pressure employed in the reactor. In view of the safety and cost, a pressure rate of 1300 psi was considered optimal. Similarly, the hydrogenation rate can also be enhanced by adding more catalyst. When $0.05 \mathrm{wt} \%$ catalyst was added, the fastest hydrogenation rate was achieved. In summary, the following optimum hydrogenation conditions were determined by using a synthesized ruthenium-based catalyst: $11.25 \mathrm{wt} \%$ solid content of XNBR latex, $140{ }^{\circ} \mathrm{C}$ of reaction temperature, $1300 \mathrm{psi}$ of hydrogen pressure and $0.05 \mathrm{wt} \%$ catalyst. The vulcanization, mechanical performance, aging resistance and oil resistance of the produced HXNBR under the above reaction conditions were systematically investigated.
\end{abstract}

Keywords: XNBR catalytic hydrogenation; reaction kinetics; hydrogenation rate; performance testing

\section{Introduction}

Hydrogenation is a common chemical modification method for unsaturated olefines. The physical and chemical performances of hydrogenated polymers such as hydrogenated NBR and hydrogenated NR have been improved compared to those of unhydrogenated polymers [1-5]. Compared to nitrile rubber (NBR), hydrogenated nitrile rubber (HNBR) presents better heat and heat oxygen aging resistance while maintaining the original oil and wear resistance of NBR. Furthermore, the mechanical performance of HNBR, such as the tensile strength and elongation ratio, are significantly improved [1]. Therefore, HNBR has been widely used in aerospace, petroleum exploration, hoses, seals and automotive engine rubber parts.

The solution hydrogenation of NBR has been successfully industrialized, which can be carried out by following either a homogeneous or a heterogeneous catalysis route [6,7]. 
Based on a kinetic analysis of the hydrogenation process via a homogeneous catalytic route, $\mathrm{Ai}$ et al. found that a hydrogenation degree of $75 \mathrm{~mol} \%$ was achieved with $6 \mathrm{mg}$ Grubbs II catalyst at $3 \mathrm{~h}$ in $100 \mathrm{~mL}$ toluene solution of $1.0 \mathrm{~g}$ NBR under 725 psi hydrogen $\left(\mathrm{H}_{2}\right)$ pressure and at $55{ }^{\circ} \mathrm{C}$ [8]. In the case of heterogeneous catalysis [9-12], silica and carbon nanotubes were introduced as catalyst carriers for hydrogenation reaction. However, the solution hydrogenation requires large amounts of organic solvents and cumbersome operations, which not only pollute the environment but also increase production costs [13].

In view of the fact that diene polymers are usually synthesized by semi-batch emulsion polymerization with a final product state as an emulsion, latex hydrogenation has attracted wide attention recently. Emulsion hydrogenation has been successfully achieved by means of diimine or gaseous hydrogen [14,15]. In the direction of diimine hydrogenation, the hydrogenated polymer is formed through carbon-carbon double bond reduction by diamine $[16,17]$. As a result, the high-pressure gaseous hydrogen, organic solvent, transition metal catalyst and expensive hydrogenation apparatus were no longer required. Wang et al. systematically studied the hydrogenation of NBR with hydrazine hydrate and sodium periodate [18]. The hydrogenation degree of NBR could reach about $95 \mathrm{~mol} \%$ in $10 \mathrm{~h}$ at $60{ }^{\circ} \mathrm{C}$ with a dropping rate of $12 \mathrm{~mL} / \mathrm{h}$ of sodium periodate. However, the health hazard of hydrazine hydrate and concomitant gelation have to be considered.

Catalytic latex hydrogenation is usually performed under high $\mathrm{H}_{2}$ pressure. Transition metal complexes such as rhodium, ruthenium, palladium and rhodium ruthenium, are selected as catalysts [19-21]. Generally, rhodium and ruthenium catalysts are commonly employed. Liu et al. explored the hydrogenation of NBR latex using water-soluble rhodium based catalysts $\mathrm{RhCl}(\mathrm{TPPMS})_{3}$ and $\mathrm{RhCl}(\mathrm{TPPTS})_{3}$ [22]. In the absence of organic solvents, the hydrogenation degree of $0.052 \mathrm{mmol} / \mathrm{L} \mathrm{RhCl}(\mathrm{TPPMS})_{3}$ reached about $95 \mathrm{~mol} \%$ in $8.5 \mathrm{~h}$ at $100{ }^{\circ} \mathrm{C}$ under $1000 \mathrm{psi}_{2}$ pressure, whereas $\mathrm{RhCl}(\mathrm{TPPTS})_{3}$ showed low reaction activity, meaning a high degree of hydrogenation could not be achieved. Wei et al. studied the hydrogenation of nitrile butadiene latex using a Wilkinson catalyst [23]. TPP was utilized as a substitute to organic solvent to ensure the catalyst molecules penetrated into latex droplets. However, the rate of the hydrogenation reaction was very slow, regardless of the amount of catalyst added, hindering further application of this technology. Wang et al. investigated the effects of the particle size, concentration and reaction temperature of the NBR latex in the hydrogenation reaction [24]. Without any organic solvent, with the condition of $1 \mathrm{wt} \%$ catalyst dosage at $130{ }^{\circ} \mathrm{C}$ and under $1000 \mathrm{psi} \mathrm{H}_{2}$, it took about $2 \mathrm{~h}$ to achieve $95 \mathrm{~mol} \%$ conversion, which took $8 \mathrm{~h}$ with $0.5 \mathrm{wt} \%$ catalyst. The hydrogenation rate was directly proportional to the catalyst loading concentration and reaction temperature and inversely proportional to the particle size. Wang and Rempel also studied the mass transfer of hydrogen in the reaction, the role of TPP in the hydrogenation reaction and the catalytic mechanism of the Wilkinson catalyst [20,24]. It was revealed that the mass transfer of hydrogen is not the limiting step in the hydrogenation reaction, while TPP plays a role as a catalyst carrier, and a competition exists between nitrile group and catalysts. Therefore, the catalytic hydrogenation of latex is preferred compared with the aforementioned methods.

XNBR can serve as an ideal polymer-based composite matrix because of its ability to be cross-linked and cured with different reagents stemming from the existence of nitrile and carboxyl functional groups [25-28]. Carboxyl hydrogenated nitrile rubber has displayed better mechanical properties, as well as better heat and oxygen aging performance than XNBR, while retaining the above two functional groups [29]. Bhattacharjee et al. hydrogenated liquid XNBR by applying a homogeneous catalysis method [30]. A hydrogenation degree of $68 \mathrm{~mol} \%$ was achieved in L-XNBR containing 0.057 carboxyl equivalent/100 $\mathrm{g}$ and $26.1 \mathrm{wt} \%$ acrylonitrile under $391 \mathrm{psi} \mathrm{H}_{2}$ pressure and $0.18 \mathrm{mmol} / \mathrm{L}$ catalyst at $60{ }^{\circ} \mathrm{C}$ for $1 \mathrm{~h}$ in acetone solution. Note that organic solution is necessary in the reaction, which stops it from being an eco-friendly approach. Yang et al. fabricated a new type of self-crosslinking film with HXNBR latex prepared by diimide reduction [29]. The results confirmed that the HXNBR latex was able to form a self-crosslinking film. Liu et al. produced functional composites with unique photoluminescence properties, excellent mechanical properties and 
good thermal stability via reactive blending of HXNBR and modified basic zinc carbonate $\left(\mathrm{m}-3 \mathrm{Zn}(\mathrm{OH})_{2} \cdot 2 \mathrm{ZnCO}_{3}\right)$ [31]. Liu et al. also used epoxy cyclohexyl polyhedral oligomeric silsesquioxane (POSS) and HXNBR to create a novel organic-inorganic composite via chemical bonding of carboxyl and the POSS epoxy group [32].

In this paper, a ruthenium-based catalyst is prepared to achieve the direct catalytic hydrogenation of XNBR latex. The emulsion hydrogenation reaction of XNBR latex under different hydrogenation conditions in the presence of catalyst is reported. The effects of the catalyst dosage, reaction temperature, hydrogen pressure and solid content on the hydrogenation rate of XNBR latex are explored in detail. In order to obtain HXNBR latex with a high hydrogenation degree, appropriate reaction conditions are delicately selected to accelerate the corresponding hydrogenation rate. The mechanical performance, oil resistance and aging resistance of HXNBR with an XNBR conversion rate of $91.02 \mathrm{~mol} \%$ prepared under the optimal condition are also tested.

\section{Results and Discussion}

The mass transfer of catalyst in XNBR latex hydrogenation is depicted in Scheme 1. In the present experiments, a certain amount of catalyst was first added and suspended in XNBR latex (Scheme 1a). During stirring, the catalyst was gradually dispersed in latex (Scheme $1 b$ ). The catalyst molecules in contact with XNBR colloidal particles tend to penetrate into the interior (Scheme 1c). After increasing the temperature to a specified level and charging the hydrogen gas, the hydrogenation reaction of XNBR latex started. Finally, HXNBR latex was generated (Scheme 1d).

(a)

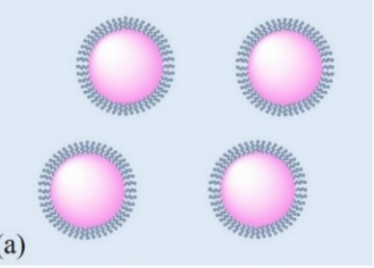

XNBR latex

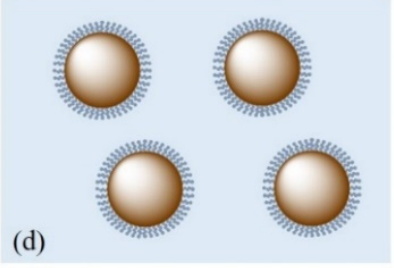

Latex hydrogenation of XNBR

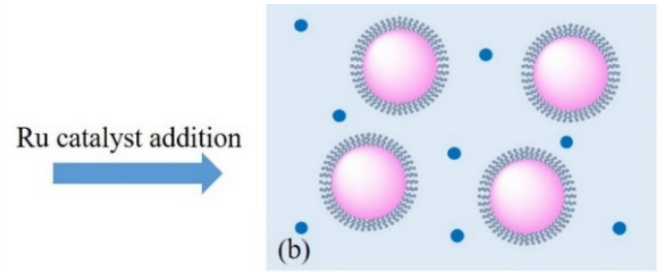

Dispersion of catalyst in XNBR latex

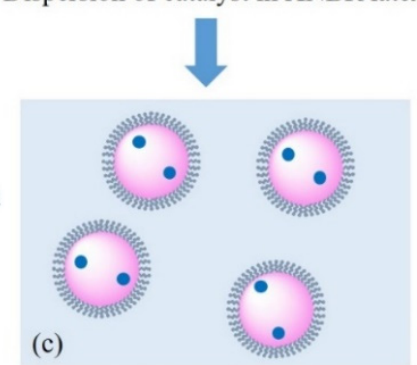

Diffusion of catalyst into latex particles
Charging hydrogen

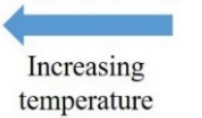

temperature

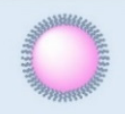

XNBR latex

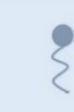

Surfactant molecule (c)

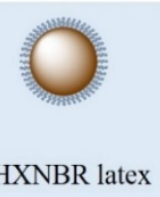

Scheme 1. Mass transfer of catalyst in XNBR latex hydrogenation. (a) XNBR latex, (b) Dispersion of catalysts in XNBR latex, (c) Diffusion of catalysts into latex particles, (d) Latex hydrogenation of XNBR.

\subsection{Fourier Transform Infrared Spectrometer (FTIR), Nuclear Magnetic Resonance Hydrogen Spectroscopy $\left({ }^{1} H\right.$ NMR) and Particle Size Analysis}

The XNBR conversion and composition of polymers could be characterized by FTIR and ${ }^{1} \mathrm{H}$ NMR. The infrared spectra and chemical composition of XNBR with distinct XNBR conversion are shown in Figure 1a. The peak at $2236 \mathrm{~cm}^{-1}$ in the infrared spectra 
results from cyano group $(C \equiv N)$, while the peak at $1700 \mathrm{~cm}^{-1}$ is caused by carbonyl group $(\mathrm{C}=\mathrm{O})$. Two types of additions exist in XNBR latex, i.e., $1-4$ and $1-2$ products. The peak at $970 \mathrm{~cm}^{-1}$ represents the characteristic peak of the 1,4-trans double bond, while the peak at $917 \mathrm{~cm}^{-1}$ is from the characteristic peak of 1,2-vinyl. There is no absorbance at $750 \mathrm{~cm}^{-1}$, the characteristic peak of the 1,4-cis double bond, which indicates that only the 1,4-trans double bond and 1,2-vinyl double bond are available in XNBR latex. Comparing the infrared spectra of XNBR with different XNBR conversions, it is found that the intensity the peaks at 970 and $917 \mathrm{~cm}^{-1}$ gradually attenuates along with the increase in XNBR conversion. Meanwhile, a new characteristic peak appears at $723 \mathrm{~cm}^{-1}$, representing the formation of $\left(\mathrm{CH}_{2}\right)_{n}, n>4$. The disappearance of characteristic peaks of 970 and $917 \mathrm{~cm}^{-1}$ signals the completion of the hydrogenation reaction. In this process, the contents of the cyano group and carbonyl group remain unchanged, indicating that the catalyst shows no selectivity for the cyano group or carbonyl group.

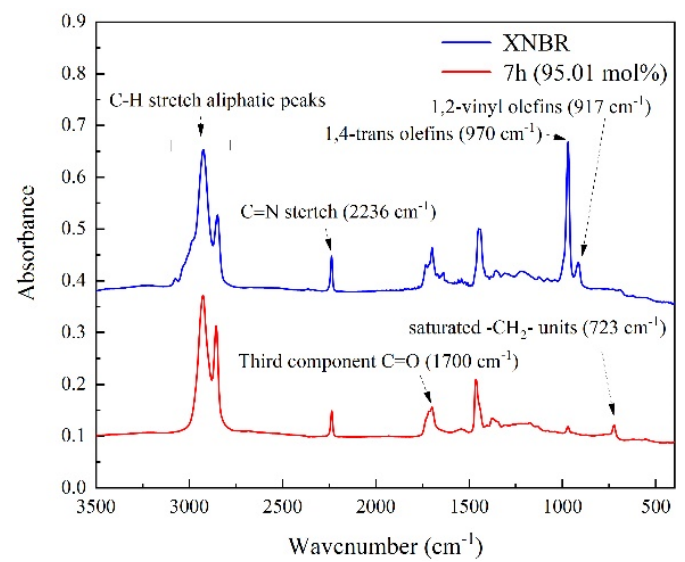

(a)
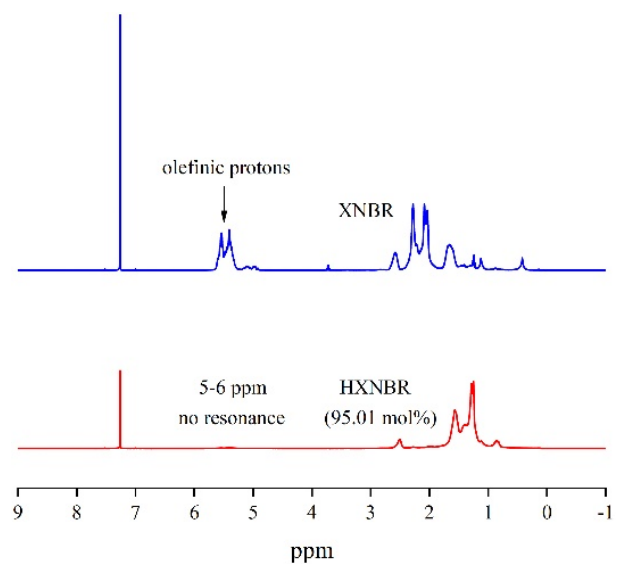

(b)

Figure 1. Representative FTIR (a) and ${ }^{1} \mathrm{H}$ NMR (b) spectra of both XNBR and HXNBR (95.01 mol\%) with an XNBR conversion rate of $95.01 \mathrm{~mol} \%$ (reaction conditions: catalyst $=0.035 \mathrm{wt} \%$, latex solid content $=11.25 \mathrm{wt} \%$, reaction temperature $=120^{\circ} \mathrm{C}$, stirring speed $=450 \mathrm{rpm}$, hydrogen pressure $=1200 \mathrm{psi}$ )

The chemical shifts of the polymer structure before and after hydrogenation are characterized by ${ }^{1} \mathrm{H}$ NMR, as shown in Figure 1b. For the original XNBR, the peak at 5.3-5.6 ppm is attributable to the trans hydrogen atom of 1,4-adduct butadiene. The peak at 4.9-5.3 ppm is attributable to 1,2-vinyl hydrogen atom. The signals of aliphatic protons are between $0.8 \mathrm{ppm}$ and $2.8 \mathrm{ppm}$. The methyl peak of methacrylic acid is between 1.0 and $1.2 \mathrm{ppm}$. When XNBR conversion is about $95.01 \mathrm{~mol} \%$, it can be clearly seen that the peak representing olefin almost disappeared, which suggests that unsaturated double bonds have been hydrogenated.

In order to explore whether the hydrogenation process affects the stability of XNBR latex, the particle size of XNBR before and after hydrogenation is compared. As shown in Figure 2, the particle size of XNBR basically remains constant before and after hydrogenation. The average size of XNBR particle before hydrogenation is about $109 \mathrm{~nm}$, while HXNBR particle after hydrogenation is about $113 \mathrm{~nm}$, suggesting that the particle size of polymers is not altered by hydrogenation reaction. In conclusion, the hydrogenation process does not affect the stability of XNBR latex.

\subsection{Effect of Latex Solid Content}

The basic hydrogenation conditions were set as followed: $11.25 \mathrm{wt} \%$ of solid content, $120{ }^{\circ} \mathrm{C}$ of reaction temperature, $1200 \mathrm{psi}$ of hydrogen pressure and $0.035 \mathrm{wt} \%$ of catalyst. Orthogonal tests were implemented to ascertain the optimum conditions.

The solid content of latex plays an important role in the emulsion hydrogenation of XNBR. A series of hydrogenation experiments with different solid content levels of latex 
were carried out to explore the effects on the hydrogenation rate. Figure 3a shows the dependence of XNBR conversion on the latex solid content. It can be seen that after increasing the latex solid content from 11.25 to $45.00 \mathrm{wt} \%$, the XNBR conversion rate drops. With $11.25 \mathrm{wt} \%$ latex solid content, the XNBR conversion can reach $95.01 \mathrm{~mol} \%$ in $7 \mathrm{~h}$, which represents the shortest time required for an XNBR conversion rate of $95 \mathrm{~mol} \%$. As the latex solid content rises to $45.00 \mathrm{wt} \%$, the XNBR conversion rate can barely reach $85.10 \mathrm{~mol} \%$ in $10 \mathrm{~h}$. Figure $3 \mathrm{~b}$ shows the average hydrogenation rate every hour with different latex solid content levels. As shown in Figure 3b, the average hydrogenation rate decreases with increased latex solid content. With low solid content levels, the instantaneous hydrogenation rate decreases with the increase in reaction time. However, the instantaneous hydrogenation rate tends to be a constant at $45.00 \mathrm{wt} \%$ solid content. Viscosity affects the dispersion of the catalyst, while viscosity is generally related to the solid content. As shown in Figure 4, the latex viscosity is monitored, with solid content levels ranging from 11.25 to $45.00 \mathrm{wt} \%$. With the latex solid content increasing from 11.25 to $45.00 \mathrm{wt} \%$, the viscosity increases from 1.93 to $44.40 \mathrm{mPa} \cdot \mathrm{s}$. The thickening effect arising from the high solid content deteriorates the dispersion of the catalyst in latex. As a result, the hydrogenation reaction rate is retarded.

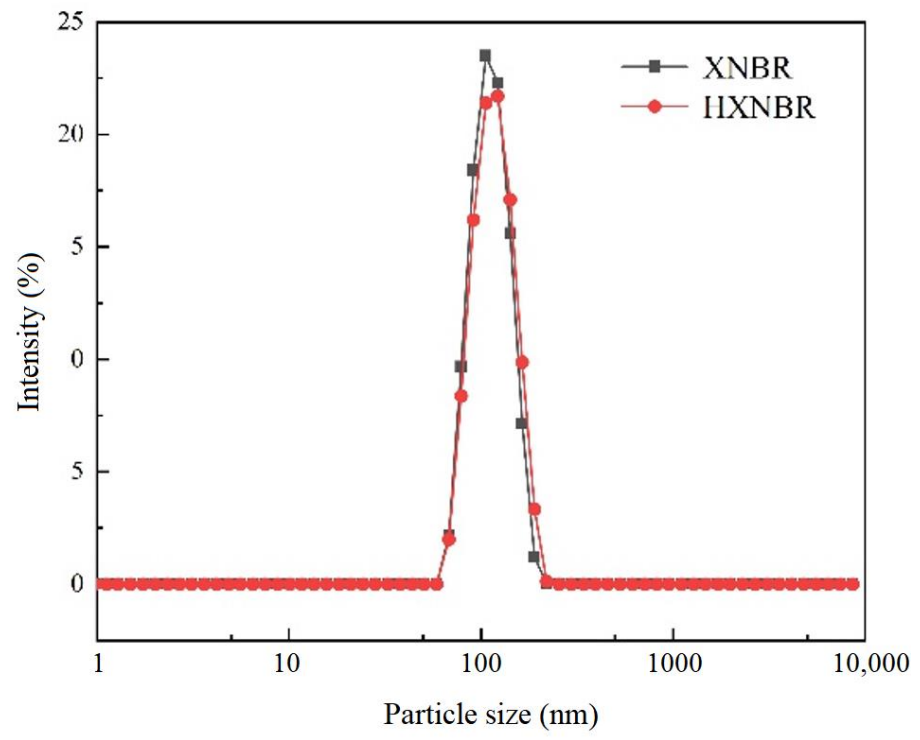

Figure 2. The size distribution of XNBR particles in latex before and after hydrogenation.

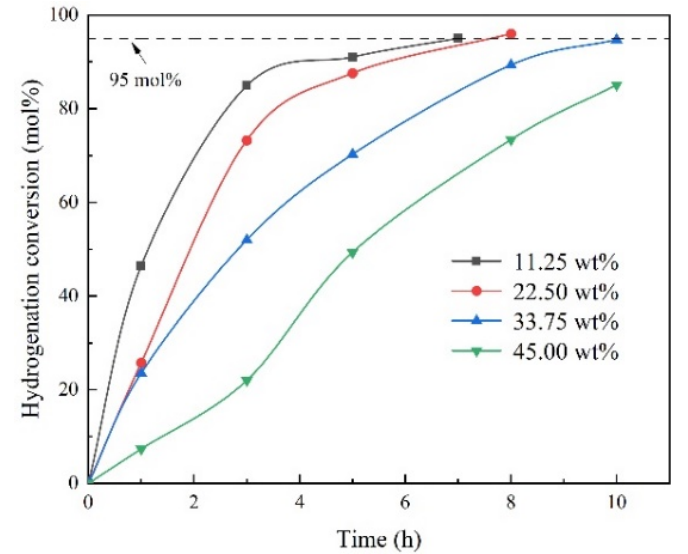

(a)

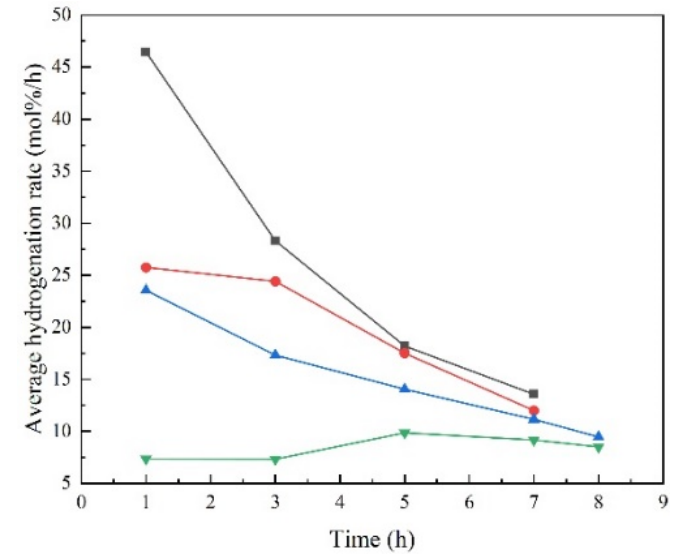

(b)

Figure 3. The XNBR conversion (a) and average hydrogenation (b) rates with different XNBR latex solid content levels. The same reaction conditions were applied as in Figure 1. 


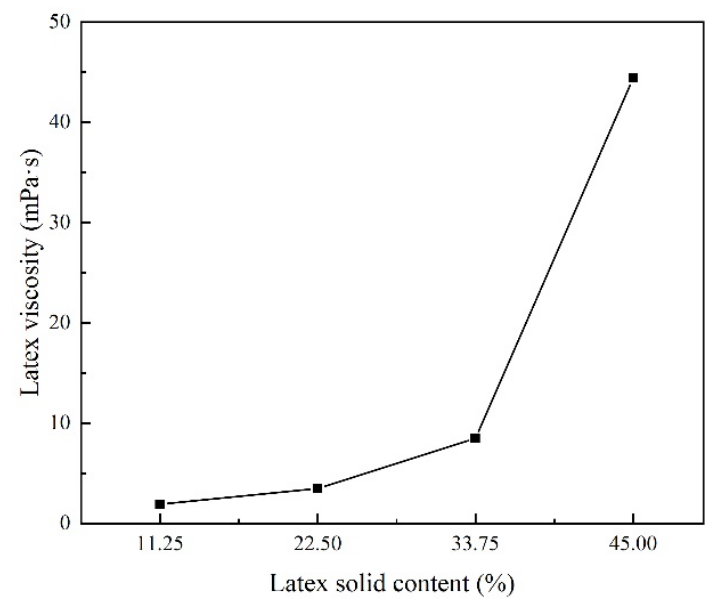

Figure 4. The dependence of the XNBR latex viscosity on the solid content, with content levels ranging from $11.25 \mathrm{wt} \%$ to $45.00 \mathrm{wt} \%$.

\subsection{Effect of Reaction Temperature}

In the hydrogenation reaction of XNBR latex, the reaction temperature acts as another key factor controlling the catalytic procedure. Figure 5 shows the effects of the reaction temperature on the hydrogenation rate of XNBR. As shown in Figure 5a, as the temperature varies from 120 to $160{ }^{\circ} \mathrm{C}$, the XNBR conversion rate first increases and then declines at a critical point. At 130 or $140{ }^{\circ} \mathrm{C}$, the XNBR conversion reaches $95 \mathrm{~mol} \%$ in $5 \mathrm{~h}$. At $120^{\circ} \mathrm{C}$, the hydrogenation rate of $95 \mathrm{~mol} \%$ takes $7 \mathrm{~h}$, which is comparable with that observed at $150{ }^{\circ} \mathrm{C}$. As the highest temperature of $160^{\circ} \mathrm{C}$ is applied, the hydrogenation rate slows down, with an XNBR conversion rate of $50.62 \mathrm{~mol} \%$ in $7 \mathrm{~h}$. It is speculated that the temperature functions by influencing the catalyst activity. In low-temperature regions, upon increasing reaction temperature, the catalytic activity is enhanced gradually. The maximum catalytic activity is reached between 130 and $140{ }^{\circ} \mathrm{C}$. By further increasing reaction temperature, the catalyst starts to lose its catalytic activity, so that the hydrogenation rate decreases in high-temperature zones. Figure $5 \mathrm{~b}$ shows the average hydrogenation rate every hour under different reaction temperatures. As shown in Figure 5b, the average hydrogenation rate first increases and then declines at a critical point with an increase in reaction temperature, while the instantaneous hydrogenation rate decreases upon increasing time. Therefore, $140^{\circ} \mathrm{C}$ is selected as the best reaction temperature in our reactions.

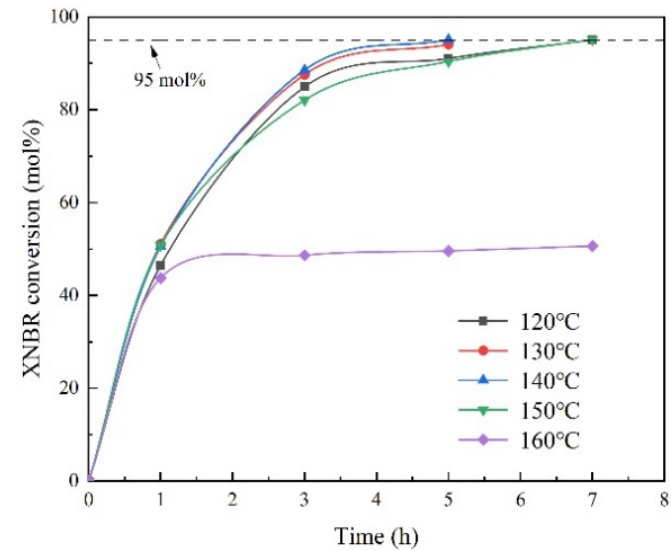

(a)

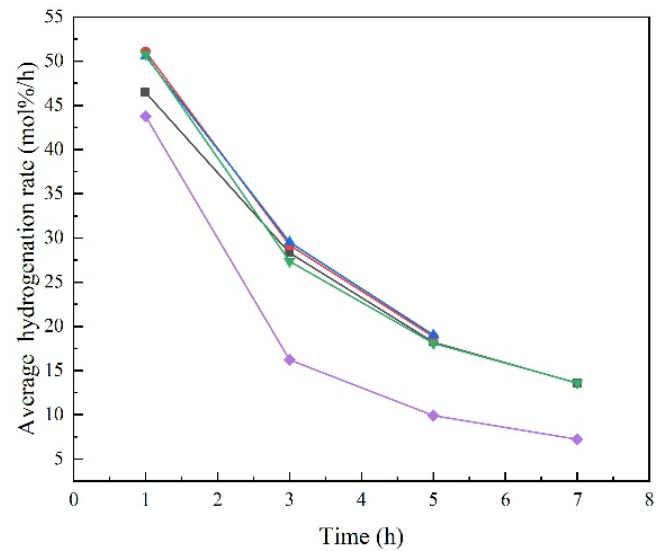

(b)

Figure 5. The XNBR conversion (a) and average hydrogenation (b) rates under different reaction temperatures.

\subsection{Effect of Catalyst Dosage}

Intuitively, the catalyst dosage can accelerate the hydrogenation rate in the XNBR emulsion hydrogenation reaction. As shown in Figure 6a, the XNBR conversion rate increases 
significantly with the increase in catalyst dosage, as expected. While keeping other terms of the basic hydrogenation condition unchanged, the XNBR conversion can reach $91.03 \mathrm{~mol} \%$ in $9 \mathrm{~h}$ with a dose of $0.025 \mathrm{wt} \%$. By applying $0.035 \mathrm{wt} \%$ catalyst, the hydrogenation rate is dramatically accelerated, leading to $95.01 \mathrm{~mol} \%$ XNBR conversion in $7 \mathrm{~h}$. With $0.05 \mathrm{wt} \%$ catalyst, the XNBR conversion of $95.61 \mathrm{~mol} \%$ is reached in $5 \mathrm{~h}$. With a greater catalyst dosage in the reactor, more catalyst molecules are attached onto the colloidal particles, which boosts the efficiency of reducing $\mathrm{C}=\mathrm{C}$ bonds, meaning the hydrogenation rate is improved. Finally, it can be seen that the dependence of the hydrogenation rate on dosage weakens when more catalyst added. As shown in Figure $6 b$, the average hydrogenation rate decreases with increased catalyst dosages. The instantaneous hydrogenation rate decreases upon increasing time, which proves that the utilization efficiency of the catalyst is reduced. Therefore, $0.05 \mathrm{wt} \%$ catalyst is the optimal choice.

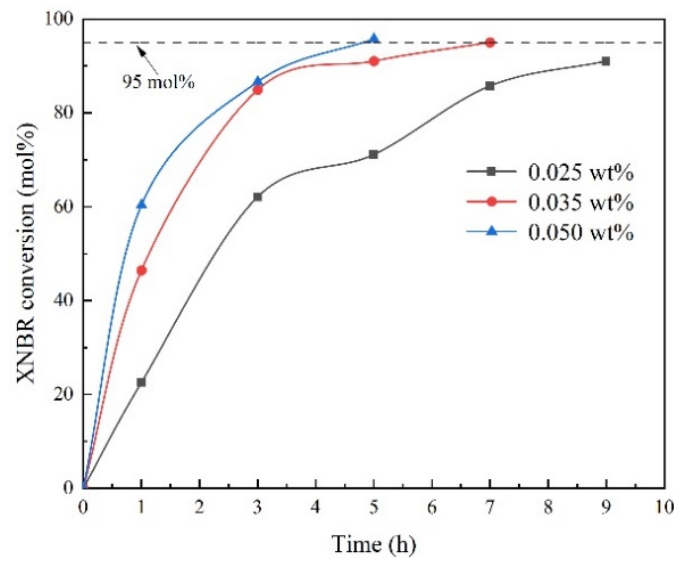

(a)

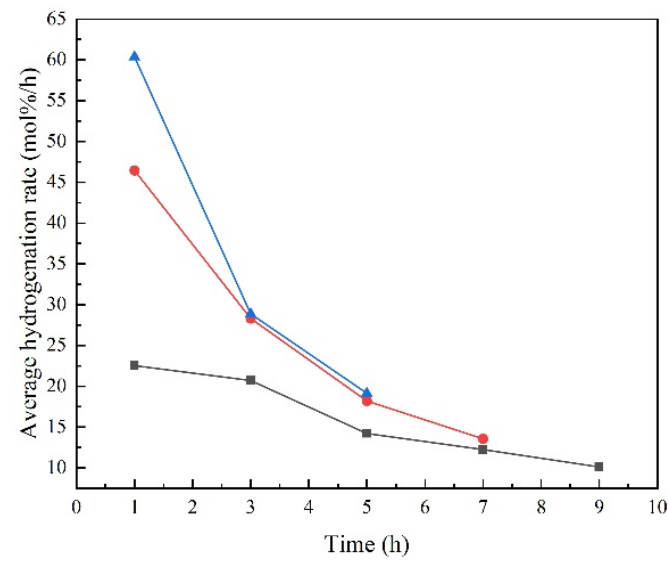

(b)

Figure 6. The XNBR conversion (a) and average hydrogenation (b) rates recorded with different catalyst dosages.

\subsection{Effect of Hydrogen Pressure}

The hydrogen pressure is also an important parameter affecting the hydrogenation rate of XNBR latex. Figure 7a shows the effect of hydrogen pressure on the hydrogenation rate. As shown in Figure 7, the XNBR conversion rate gradually increases as the hydrogen pressure grows. At 1100 psi, it takes $9 \mathrm{~h}$ for the XNBR conversion to reach $95.38 \mathrm{~mol} \%$. With a hydrogen pressure of $1500 \mathrm{psi}$, the XNBR conversion can reach $94.25 \mathrm{~mol} \%$ in only $3 \mathrm{~h}$. It is posited that higher hydrogen pressure provides more possible hydrogen contacts with colloidal particles, which speeds up the hydrogenation rate. As shown in Figure 7b, the average hydrogenation rate decreases with increases in hydrogen pressure. Considering the safety and cost, 1300 psi is selected as the optimal hydrogen pressure.

\subsection{HXNBR Performance Test}

The HXNBR compound was produced according to the formula provided in Table 1 to test its vulcanization, mechanical performance, oil resistance and heat-oxygen aging resistance.

Table 1. Vulcanization properties of the HXNBR compound.

\begin{tabular}{ccccccc}
\hline $\begin{array}{c}\text { Vulcanization } \\
\text { Characteristics }\end{array}$ & Ts $1 /$ min & $\mathbf{T}_{\mathbf{1 0}} / \mathbf{m i n}$ & $\mathrm{T}_{\mathbf{9 0}} / \mathbf{m i n}$ & $\mathbf{M}_{\mathrm{L}} / \mathbf{d N m}$ & $\mathbf{M}_{\mathbf{H}} / \mathbf{d N m}$ & $\mathbf{M}_{\mathbf{H}}-\mathbf{M}_{\mathrm{L}} / \mathbf{d N m}$ \\
\hline HXNBR & 0.42 & 0.52 & 4.36 & 4.4 & 22.8 & 18.4 \\
\hline
\end{tabular}




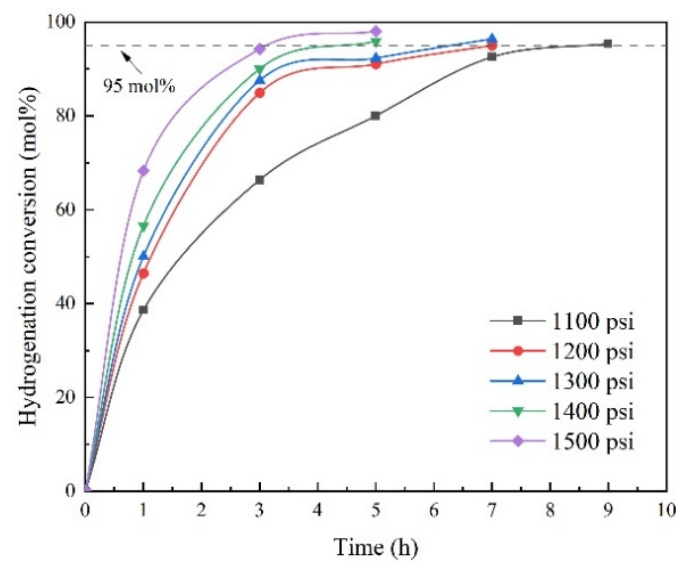

(a)

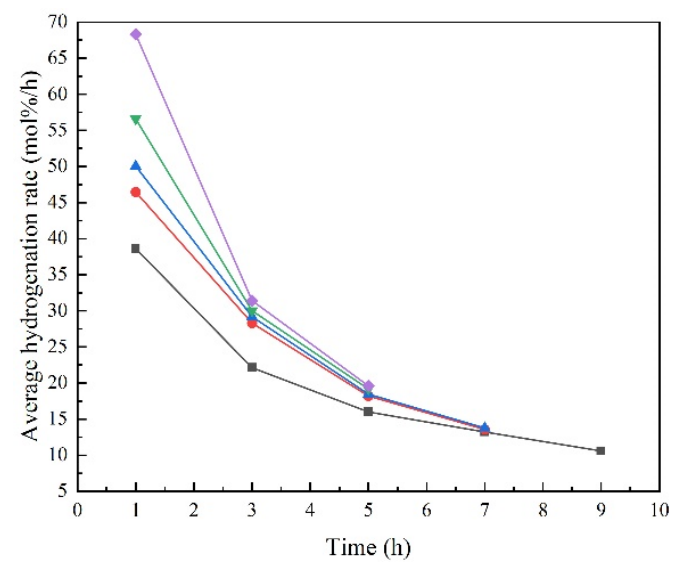

(b)

Figure 7. The XNBR conversion (a) and average hydrogenation (b) rates under a series of hydrogen pressure increases.

\subsubsection{Vulcanization Characteristics of HXNBR Compound}

The vulcanization characteristics of the produced HXNBR compound were tested using a moving die rheometer. The scorch time $\mathrm{T}_{10}$, positive vulcanization time $\mathrm{T}_{90}$, maximum torque $\mathrm{M}_{\mathrm{H}}$ and minimum torque $\mathrm{M}_{\mathrm{L}}$ were recorded, as presented in Table 1 . Figure 8 shows the vulcanization curve of HXNBR at $180^{\circ} \mathrm{C}$. As shown in Table 1 and Figure 8, the HXNBR compound had a fast vulcanization speed, high crosslinking degree and good heat resistance.

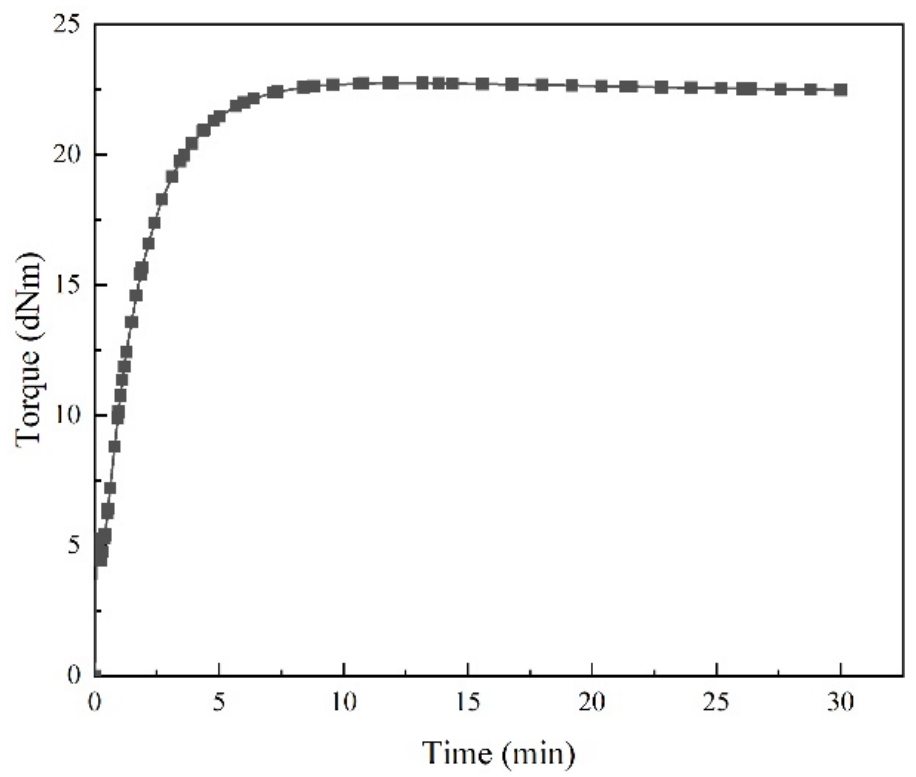

Figure 8. Vulcanization curve of HXNBR.

\subsubsection{Analysis of the Heat-Oxygen Aging Performance}

The mechanical performance results for the HXNBR compound before and after aging are provided in Table 2 . The tensile strength of the HXNBR compound before aging was 28.6 MPa, the Shore A hardness reached 79, while the elongation at break was $193 \%$. In comparison, after aging, both the hardness and tensile strength of HXNBR were obviously increased, yet the elongation at break was reduced. After placing the compound in a high-temperature environment for a long time, further cross-links in the rubber mixture meant the crosslinking density was too high, resulting in increased hardness and tensile strength and decreased elongation at break. 
Table 2. Mechanical properties of the HXNBR compound before and after aging.

\begin{tabular}{cccc}
\hline Properties & Before Aging Test & After Aging Test & Difference \\
\hline Hardness (3 s)/Shore A & 79 & 88 & 6 \\
Tensile strength/MPa & 28.6 & 31 & 2.4 \\
Elongation at break/\% & 193 & 128 & -65 \\
\hline
\end{tabular}

\subsubsection{Oil Resistance Analysis}

For the HXNBR compound, in addition to the hot air aging performance, the oil resistance also serves as an important performance index. Tables 3 and 4 show the mechanical performance of the HXNBR compound before and after soaking in IRM 901 and 903 standard oils at $150{ }^{\circ} \mathrm{C}$ for $72 \mathrm{~h}$. After soaking in IRM 901 standard oil, both the hardness and tensile strength of the HXNBR compound were enhanced, whereas the elongation at break was reduced. It is speculated that the rubber chains with low molecular weight in the compound enter the oil phase after a long period of soaking. After soaking in IRM 903 standard oil, the hardness, tensile strength and elongation at break were all debased. Differing from the above, the oil entered the compound during prolonged immersion in IRM 903 oil.

Table 3. Mechanical performance of the HXNBR compound before and after the oil resistance test with IRM 901 standard oil.

\begin{tabular}{cccc}
\hline Properties & Before Oil Resistance Test & After Oil Resistance Test & Difference \\
\hline Hardness (3 s)/Shore A & 79 & 88 & 9 \\
Tensile strength/MPa & 28.6 & 34.7 & 6.1 \\
Elongation at break/\% & 193 & 154 & -39 \\
\hline
\end{tabular}

Table 4. Mechanical performance of the HXNBR compound before and after the oil resistance test of IRM 903 standard oil.

\begin{tabular}{cccc}
\hline Properties & Before Oil Resistance Test & After Oil Resistance Test & Difference \\
\hline Hardness (3 s)/Shore A & 79 & 71 & -9 \\
Tensile strength/MPa & 28.6 & 27.3 & -1.3 \\
Elongation at break/\% & 193 & 163 & -30 \\
\hline
\end{tabular}

\section{Materials and Methods}

\subsection{Materials}

Ultra-high purity hydrogen (99.99\%) and liquid nitrogen were used as received (Qingdao Ludong Gas Co., Ltd., Qingdao, China). XNBR latex was purchased from ARLANXEO. [1,3Bis(2,4,6-trimethylphenyl)-2-imidazolidinylidene]dichloro(2,4-diisopropoxyphenylmethylene) ruthenium was prepared according to the literature [33]. Deionized water used in the experiment was self-made in the laboratory.

Zinc oxide $(\mathrm{ZnO})$ and stearic acid (SA) were purchased from Rhine Chemical Co., Ltd., Qingdao, China. Carbon black, brand N550, was purchased from Cabot Chemical Co., Ltd., Shanghai, China. Triallyl isocyanate (TAIC) was purchased from Jinchangsheng Technology Co., Ltd., Guangzhou, China. Other raw materials were commercially available industrial products.

\subsection{Catalytic Hydrogenation of XNBR Latex}

The catalytic hydrogenation of XNBR latex was carried out in a $300 \mathrm{~mL}$ Parr reactor. Firstly, XNBR latex with a specified solid content prepared by water solution was directly mixed with a certain amount of catalyst. The mixture was then rapidly vented through three nitrogen cycles and bubbled at about $30 \mathrm{psi}$ for $1 \mathrm{~h}$ at room temperature and a fixed stirring rate of $200 \mathrm{rpm}$. Afterwards, the mixture was heated to a specified temperature and stabilized for half an hour at $450 \mathrm{rpm}$, then hydrogen gas at a certain pressure was 
introduced into the reactor to start the hydrogenation of XNBR latex. The reaction temperature $\left(120-160{ }^{\circ} \mathrm{C}\right)$, stirring speed $(450 \mathrm{rpm})$ and hydrogen pressure (1100-1500 psi) were all kept constant for $10 \mathrm{~h}$. An amount of samples was extracted through the sampling tube every hour, based on which XNBR conversion was evaluated with a Fourier transform infrared spectrometer (FTIR). When the XNBR conversion reached more than $95 \mathrm{~mol} \%$ or was unchanged, the reaction was ended manually and the final product was obtained after cooling down to room temperature and depressurization.

\subsection{Basic Formula}

The basic formula of HXNBR compound is shown in Table 5.

Table 5. Formulation of the HXNBR compound.

\begin{tabular}{cccccccc}
\hline Recipe & HNBR & ZnO & SA & N550 & TOTM & F-40 & TAIC \\
\hline Content $(\mathrm{phr})$ & 100 & 5 & 1 & 50 & 8 & 8 & 2 \\
\hline
\end{tabular}

\subsection{Rubber Mixing Process}

Using a HAPRO torque rheometer (filling coefficient 0.8), internal mixing was performed at $60{ }^{\circ} \mathrm{C}$ and $50 \mathrm{rpm}$. In the first stage, HXNBR was treated in the internal mixer for $2 \mathrm{~min}$ before SA and $\mathrm{ZnO}$ were added. Then, 1 min later, the first halves of N550 and TOTM were put into the mixer. After mixing for another $1.5 \mathrm{~min}$, the second halves of N550 and TOTM were added. The first stage of mixing was finished in $8 \mathrm{~min}$. The first section of master rubber was triangular, which was wrapped six times with an open mixer with a roll distance of $0.3 \mathrm{~mm}$ and passed through the roll with a mixing mill with a roll pitch of $1.0 \mathrm{~mm}$, then parked at room temperature. In the second stage of mixing, the processed rubber compound was further mixed for 6 min after F-40 and TAIC were directly added. The milling run was repeated as in the first stage.

\subsection{Characterization}

\subsubsection{Latex Structure Composition and Hydrogenation}

The structure composition and XNBR conversion of latex were determined by FTIR (Bruker tensor II, Karlsruhe, Germany). In the hydrogenation reaction, the latex samples were demulsified with anhydrous ethanol and the obtained dried solid rubber was then dissolved in butanone. The butanone solution of hydrogenated HXNBR was cast on potassium bromide tablets and dried for FTIR analysis.

The degree of hydrogenation was calculated based on the corresponding absorbance (A) peaks at 2236, 970 and $723 \mathrm{~cm}^{-1}$ from the IR spectra $[24,34,35]$. The $2236 \mathrm{~cm}^{-1}$ peak represents the cyano group $(C \equiv N)$, while the $970 \mathrm{~cm}^{-1}$ peak corresponds to the $C=C$ (1,4-trans). The new generated peak at $723 \mathrm{~cm}^{-1}$ is assigned to $\left(\mathrm{CH}_{2}\right)_{n}, n>4$.

Let $\bar{A}_{(723)}=A_{(723)} / A_{(2236)}, \bar{A}_{(970)}=A_{(970)} / A_{(2236)}$, while:

$$
F=1+\bar{A}_{(723)} / K_{(723)}+\bar{A}_{(970)} / K_{(970)}
$$

where $K_{(723)}=0.255$ and $K_{(970)}=2.3$ are constants specific to the HXNBR polymer $[24,34,35]$.

Then, the relative amount of $\mathrm{C}=\mathrm{C}$ remaining in $\mathrm{HXNBR}$ is computed as:

$$
\mathrm{C}_{(\mathrm{BR})}=\bar{A}_{(970)} /\left[K_{(970)} F\right]
$$

and the relative number of methylene groups formed through hydrogenation of $\mathrm{C}=\mathrm{C}$ in $\mathrm{XNBR}$ is evaluated as:

$$
C_{(\mathrm{HBR})}=\bar{A}_{(723)} /\left[K_{(723)} F\right]
$$

Finally, the degree of hydrogenation can be calculated as:

$$
\text { Degree of hydrogenation }(\mathrm{mol}) \%=100-C_{(\mathrm{BR})} /\left[C_{(\mathrm{BR})}+C_{(\mathrm{HBR})}\right] \times 100
$$


The hydrogenation conversion and structural composition were confirmed by ${ }^{1} \mathrm{H}$ NMR recorded on Bruker $300 \mathrm{MHz}$ spectrometers from Bruker Biospin GmbH (Karlsruhe, Germany). Here, $5 \mathrm{mg}$ dry solid XNBR or HXNBR was dissolved in $0.5 \mathrm{~mL}$ deuterated chloroform solution for ${ }^{1} \mathrm{H}$ NMR characterization.

\subsubsection{Particle Size}

The intensity distribution and Z-average particle size distribution of XNBR nanoparticles were determined using the DLS (Zetasizer Nano ZS, Malvern Instruments, Worcestershire, UK) at room temperature.

\subsubsection{Rotation Viscosity}

The viscosity of the XNBR latex with different solid content levels was measured using an NBJ-1B rotary viscometer from Changji Geological Instrument Co., Ltd., Shanghai, China.

\subsubsection{Rubber Compound Analysis and Test}

HXNBR was mixed using an RM-200C HAPRO torque rheometer (HAPRO Electric Technology Co., Ltd., Harbin, China).

According to GB/T 16584-1996, the rubber compound was tested using an MDR Premier Moving Die Rheometer (American Alpha Technology Company, New York, NY, USA) at $180{ }^{\circ} \mathrm{C}$ for $30 \mathrm{~min}$.

According to GB/T 528-2009 and GB/T 529-2008, the tensile properties of vulcanizates were tested using a universal tensile testing machine (Zwick Roell group, Ulm, Germany). The tensile temperature was set to $25^{\circ} \mathrm{C}$ and the tensile rate was fixed at $500 \mathrm{~mm} / \mathrm{min}$. According to GB 531-1983, the hardness of the vulcanized rubber was tested using a Digi Test II full-function rubber hardness tester (Bareiss Instrument Co., Ltd., Oberdischingen, Germany).

According to GB/T 3512-2014, an FD115 hot air circulation oven (BINDER) was used for aging test at $150{ }^{\circ} \mathrm{C}$ for $72 \mathrm{~h}$. According to GB/T 1690-2010, a GT-7040-L thermostatic oil bath (Taiwan GOTECH Testing Machines Inc., Taichung, Taiwan) was used for oil resistance testing. The oil resistance was tested at $150{ }^{\circ} \mathrm{C}$ for $72 \mathrm{~h}$.

\section{Conclusions}

In summary, a ruthenium-based catalyst $\left(\mathrm{C}_{34} \mathrm{H}_{44} \mathrm{C}_{12} \mathrm{~N}_{2} \mathrm{O}_{2} \mathrm{Ru}\right)$ was prepared to obtain HXNBR through direct hydrogenation of the XNBR latex. The factors affecting XNBR hydrogenation in the latex, such as the catalyst dosage, solid content, reaction temperature and hydrogen pressure, were systematically studied. We found that the variations in hydrogenation conditions had little impact on the particle size in the emulsion. Increasing the solid content reduced the hydrogenation rate, while the XNBR conversion reached $95.01 \mathrm{~mol} \%$ in $7 \mathrm{~h}$ with $11.25 \mathrm{wt} \%$ solid content. On the contrary, higher hydrogen pressure effectively improved the hydrogenation rate, while the XNBR conversion reached $94.25 \mathrm{~mol} \%$ in nearly $3 \mathrm{~h}$ at 1500 psi. Within the temperature range explored here, the fastest hydrogenation rate was obtained at $140{ }^{\circ} \mathrm{C}$, with $95.10 \mathrm{~mol} \%$ XNBR conversion in $5 \mathrm{~h}$. As the catalyst amount can significantly increase the hydrogenation rate, $0.05 \mathrm{wt} \%$ catalyst ensured $95.61 \mathrm{~mol} \%$ XNBR conversion in $5 \mathrm{~h}$. Taking account of the hydrogenation rate and experimental safety, the optimum hydrogenation conditions are listed as follows: $11.25 \mathrm{wt} \%$ solid content, $140{ }^{\circ} \mathrm{C}$ reaction temperature, 1300 psi hydrogen pressure and $0.05 \mathrm{wt} \%$ catalyst dosage. The vulcanization, mechanical properties, aging and oil resistance of the self-made HXNBR were tested after mixing. By choosing suitable hydrogenation conditions, a minimal dose of catalyst required in hydrogenation, while the hydrogenation rate is unaffected. This may have important implications in the hydrogenation of XNBR latex in the rubber industry. 


\begin{abstract}
Author Contributions: Conceptualization, Y.L., J.S. and H.W.; methodology, Y.L. and H.W.; validation, X.L., Y.F., S.Z. and D.Z.; formal analysis, X.L. and H.C.; investigation, X.L. and Y.F.; resources, Y.L., J.S., S.Z. and H.W.; data curation, X.L., Y.F. and D.Z.; writing-original draft preparation, X.L.; writing-review and editing, Y.L., J.S. and H.W.; visualization, Y.L., J.S. and H.W.; supervision, H.W.; funding acquisition, Y.L., J.S., S.Z. and H.W. All authors have read and agreed to the published version of the manuscript.

Funding: This research was funded by the Natural Science Foundation of Shandong Province, grant numbers ZR2019MB001 and ZR2018BEM014; the Taishin Scholar Project of Shandong Province, grant number ts201712047; the National Natural Science Foundation of China, grant numbers 51802170, 21801150 and 21674055; and the Introduction of Urgently Needed Talents In Key Supporting Regions of Shandong Province project (Shangdong Dongdu Auto Parts Co., Ltd., Rizhao, China).
\end{abstract}

Conflicts of Interest: The authors hereby declare no conflict of interest.

\title{
References
}

1. Wang, H.; Yang, L.; Rempel, G.L. Homogeneous Hydrogenation Art of Nitrile Butadiene Rubber: A Review. Polym. Rev. 2013, 53, 192-239. [CrossRef]

2. Piya-areetham, P.; Prasassarakich, P.; Rempel, G.L. Organic solvent-free hydrogenation of natural rubber latex and synthetic polyisoprene emulsion catalyzed by water-soluble rhodium complexes. J. Mol. Catal. A Chem. 2013, 372, 151-159. [CrossRef]

3. Ji, M.; Yue, D.; Wu, X.; Zhao, S.; Sun, S.; Zhang, L. Structure and performance of hydrogenated natural rubber prepared by the latex method. Plast. Rubber Compos. 2017, 46, 245-250. [CrossRef]

4. Schulz, G.A.S.; Comin, E.; de Souza, R.F. Catalytic hydrogenation of nitrile rubber using palladium and ruthenium complexes. J. Appl. Polym. Sci. 2007, 106, 659-663. [CrossRef]

5. Kotzabasakis, V.; Georgopoulou, E.; Pitsikalis, M.; Hadjichristidis, N.; Papadogianakis, G. Catalytic conversions in aqueous media: A novel and efficient hydrogenation of polybutadiene-1,4-block-poly(ethylene oxide) catalyzed by Rh/TPPTS complexes in mixed micellar nanoreactors. J. Mol. Catal. A Chem. 2005, 231, 93-101. [CrossRef]

6. Parent, J.S.; Mcmanus, N.T.; Rempel, G.L. Selectivity of the $\mathrm{OsHCl}(\mathrm{CO})\left(\mathrm{O}_{2}\right)\left(\mathrm{PCy}_{3}\right)_{2}$ catalyzed hydrogenation of nitrile butadiene rubber. J. Appl. Polym. Sci. 2001, 79, 1618-1626. [CrossRef]

7. Yue, D.M.; Shen, Z.M.; Xu, R.Q.; Wei, Y.K. A New Bimetallic Complex Catalyst for NBR Hydrogenation and Properties of Hydrogenated NBR. J. Elastomers Plast. 2016, 34, 225-237. [CrossRef]

8. Ai, C.; Gong, G.; Zhao, X.; Liu, P. Selectively catalytic hydrogenation of nitrile-butadiene rubber using Grubbs II catalyst. Macromol. Res. 2017, 25, 461-465. [CrossRef]

9. Zou, R.; Li, C.; Zhang, L.; Yue, D. Selective hydrogenation of nitrile butadiene rubber (NBR) with rhodium nanoparticles supported on carbon nanotubes at room temperature. Catal. Commun. 2016, 81, 4-9. [CrossRef]

10. Cao, P.; Huang, C.; Zhang, L.; Yue, D. One-step fabrication of RGO/HNBR composites via selective hydrogenation of NBR with graphene-based catalyst. RSC Adv. 2015, 5, 41098-41102. [CrossRef]

11. Ge, B.; Hu, Y.; Zhang, H.; Xu, J.; Zhang, P.; Yue, Y.; Zhu, H.; Lin, S.; Yuan, P. Zirconium promoter effect on catalytic activity of Pd based catalysts for heterogeneous hydrogenation of nitrile butadiene rubber. Appl. Surf. Sci. 2021, 539, 148212. [CrossRef]

12. Zhang, P.; Zhang, H.; Wang, S.; Lei, X.; Yang, J.; Li, Z.; Zhu, H.; Bao, X.; Yuan, P. Effect of support morphology on the activity and reusability of $\mathrm{Pd} / \mathrm{SiO}_{2}$ for NBR hydrogenation. J. Mater. Sci. 2020, 55, 12876-12883. [CrossRef]

13. Ai, C.; Li, J.; Gong, G.; Zhao, X.; Liu, P. Preparation of hydrogenated nitrile-butadiene rubber (H-NBR) with controllable molecular weight with heterogeneous catalytic hydrogenation after degradation via olefin cross metathesis. React. Funct. Polym. 2018, 129, 53-57. [CrossRef]

14. Lin, X.; Pan, Q.; Rempel, G.L. Hydrogenation of nitrile-butadiene rubber latex with diimide. Appl. Catal. A Gen. 2004, 276, 123-128. [CrossRef]

15. Schulz, G.A.S.; Comin, E.; de Souza, R.F. Hydrogenation of NBR latex by diimide reduction using selenium catalysts. J. Appl. Polym. Sci. 2010, 115, 1390-1394. [CrossRef]

16. Ou, H.; Wang, Y.; Zhou, W.; Peng, X. Kinetics investigation on the hydrogenation of acrylonitrile-butadiene rubber latex by using new catalytic reaction system. Catal. Commun. 2016, 84, 183-187. [CrossRef]

17. Zhou, S.; Bai, H.; Wang, J. Hydrogenation of acrylonitrile butadiene rubber latexes. J. Appl. Polym. Sci. 2010, 91, 2072-2078. [CrossRef]

18. Wang, X.; Zhang, L.; Han, Y.; Shi, X.; Wang, W.; Yue, D. New method for hydrogenating NBR latex. J. Appl. Polym. Sci. 2013, 127, 4764-4768. [CrossRef]

19. Wang, H.; Yang, L.; Scott, S.; Pan, Q.; Rempel, G.L. Organic solvent-free catalytic hydrogenation of diene-based polymer nanoparticles in latex form. Part II. Kinetic analysis and mechanistic study. J. Polym. Sci. Part A Polym. Chem. 2012, 50, $4612-4627$. [CrossRef]

20. Wang, H.; Rempel, G.L. Organic solvent-free catalytic hydrogenation of diene-based polymer nanoparticles in latex form: Mass transfer of hydrogen in a semibatch process. J. Ind. Eng. Chem. 2015, 25, 29-34. [CrossRef] 
21. Wang, H.; Yang, L.; Rempel, G.L.; Pan, Q. Hydrogenation of a Tri-layer High Performance Elastomer: Substrate Synthesis, Catalytic Latex Hydrogenation, and Catalyst Recovery. Top. Catal. 2014, 57, 1512-1518. [CrossRef]

22. Liu, Y.; Kim, H.; Pan, Q.; Rempel, G.L. Hydrogenation of acrylonitrile-butadiene copolymer latex using water-soluble rhodium catalysts. Catal. Sci. Technol. 2013, 3, 2689-2698. [CrossRef]

23. Wei, Z.; Wu, J.; Pan, Q.; Rempel, G.L. Direct Catalytic Hydrogenation of an Acrylonitrile-Butadiene Rubber Latex Using Wilkinson's Catalyst. Macromol. Rapid Commun. 2005, 26, 1768-1772. [CrossRef]

24. Wang, H.; Pan, Q.; Rempel, G.L. Diene-based polymer nanoparticles: Preparation and direct catalytic latex hydrogenation. J. Polym. Sci. Part A Polym. Chem. 2012, 50, 2098-2110. [CrossRef]

25. Jie, H.; Sheng, J.; Xiong, Y. Sound Absorption Properties of Single-Hole Hollow Polyester Fiber Reinforced Hydrogenated Carboxyl Nitrile Rubber Composites. Autex Res. J. 2017, 17, 263-267. [CrossRef]

26. Ibarra, L.; Rodríguez, A.; Mora-Barrantes, I. Crosslinking of unfilled carboxylated nitrile rubber with different systems: Influence on properties. J. Appl. Polym. Sci. 2008, 108, 2197-2205. [CrossRef]

27. Laskowska, A.; Zaborski, M.; Boiteux, G.; Gain, O.; Marzec, A.; Maniukiewicz, W. Ionic elastomers based on carboxylated nitrile rubber (XNBR) and magnesium aluminum layered double hydroxide. Express Polym. Lett. 2014, 8, 374-386. [CrossRef]

28. Liu, Q.-X.; Ding, X.-B.; Zhang, H.-P.; Yan, X. Preparation of high-performance damping materials based on carboxylated nitrile rubber: Combination of organic hybridization and fiber reinforcement. J. Appl. Polym. Sci. 2009, 114, 2655-2661. [CrossRef]

29. Han, Y.; Mao, L.; Meng, H.; Zhang, L.; Yue, D. Novel self-crosslinking film from hydrogenated carboxylated nitrile rubber latex. J. Appl. Polym. Sci. 2014, 131, 1082-1090. [CrossRef]

30. Bhattacharjee, S.; Bhowmick, A.K.; Avasthi, B.N. Homogeneous catalytic hydrogenation of liquid carboxylated nitrile rubber. J. Polym. Sci. Part A Polym. Chem. 1992, 30, 1961-1968. [CrossRef]

31. Liu, Q.; Ren, W.; Yong, Z.; Zhang, Y.X. Hydrogenated carboxylated nitrile rubber/modified zinc carbonate basic composites with photoluminescence properties. Eur. Polym. J. 2011, 47, 1135-1141. [CrossRef]

32. Liu, Q.; Ren, W.; Zhang, Y.; Zhang, Y. Curing reactions and properties of organic-inorganic composites from hydrogenated carboxylated nitrile rubber and epoxycyclohexyl polyhedral oligomeric silsesquioxanes. Polym. Int. 2011, 60, 422-429. [CrossRef]

33. Zaja, M.; Connon, S.J.; Dunne, A.M.; Rivard, M.; Buschmann, N.; Jiricek, J.; Blechert, S. Ruthenium olefin metathesis catalysts with modified styrene ethers: Influence of steric and electronic effects. Tetrahedron 2003, 59, 6545-6558. [CrossRef]

34. Brück, D. IR spectrometric determination of the proportions of acrylonitrile, butadiene and hydrogenated butadiene in hydrogenated acrylonitrile-butadiene rubbers. Part 1. Principles. Kautsch. Gummi Kunstst. 1989, 42, 107-110.

35. Brück, D. IR spectrometric determination of the proportions of acrylonitrile, butadiene and hydrogenated butadiene in hydrogenated acrylonitrile-butadiene rubbers. Part 2. Residual double bonds in commercial HNBR products. Kautsch. Gummi Kunstst. 1989, 42, 194-197. 